\title{
Effect of nitrogen fertilizer rates on growth and oil yield of Java lemongrass (Cymbopogon winterianus Jawitt) in Thu Duc, Ho Chi Minh City
}

\author{
Thuan T. H. Pham, Tuyen A. Hoang, Anh T. L. Phan, \& Lan P. H. Nguyen* \\ Faculty of Agronomy, Nong Lam University, Ho Chi Minh City, Vietnam
}

\begin{abstract}
ARTICLE INFO
Research Paper

Received: January 23, 2021

Revised: February 12, 2021

Accepted: February 25, 2021

\section{Keywords}

Java lemongrass

Lemongrass oil

Nitrogen fertilizer

\section{${ }^{*}$ Corresponding author}

Nguyen Pham Hong Lan Email: lan.nonghoc@hcmuaf.edu.vn

ABSTRACT

Java lemongrass is commonly cultivated in Vietnam for the use in industries and traditional medicine. Currently, the application of fertilizer, especially nitrogen fertilizer, is one of the most traditional farm practices to increase production yield. A single factorial experiment was carried out in a completely randomized design, three replications to determine the suitability of nitrogen fertilizer rates on growth, leaf and oil yields of Java lemongrass. Six treatments were used in this experiment including 90, 120, $150,180,210,240 \mathrm{~kg} \mathrm{~N} / \mathrm{ha}$ and applying $90 \mathrm{~kg} \mathrm{~N} / \mathrm{ha}$ as control. Fertilizer base for treatments (for 1 ha) included 20 tons of cow dung compost, $60 \mathrm{~kg} \mathrm{P}_{2} \mathrm{O}_{5}$ and $60 \mathrm{~kg} \mathrm{~K} \mathrm{~K}_{2} \mathrm{O}$. The application of $120 \mathrm{~kg} \mathrm{~N} / \mathrm{ha}$ significantly improved the growth of Java lemongrass as plant height $(97.0 \mathrm{~cm} /$ plant $)$, average number of leaves (197.1 leaves/plant), average weight of leaves per plant (198.7 $\mathrm{g} /$ plant), fully leaf yield (9.4 tons/ha/2 harvest times), essential oil content $(1.0 \% \mathrm{FW})$ and economic oil yield $(97.8 \mathrm{~kg} / \mathrm{ha} / 2$ harvests).
\end{abstract}

Cited as: Pham, T. T. H., Hoang, T. A., Phan, A. T. L., \& Nguyen, L. P. H. (2021). Effect of nitrogen fertilizer rates on growth and oil yield of Java lemongrass (Cymbopogon winterianus Jawitt) in Thu Duc, Ho Chi Minh City. The Journal of Agriculture and Development 20(1), 10-16. 


\title{
Ảnh hưởng của liều lượng phân đạm đến sinh trưởng và năng suất tinh dầu của cây sả Java (Cymbopogon winterianus Jawitt) tại Thủ Đức, thành phố Hồ Chí Minh
}

\author{
Phạm Thị Hồng Thuận, Hoàng Anh Tuyên, Phan Thị Lan Anh \& Nguyễn Phạm Hồng Lan* \\ Khoa Nông Học, Trường Đại Học Nông Lâm TP.HCM, TP. Hồ Chí Minh
}

THÔNG TIN BÀI BÁO
Bài báo khoa học
Ngày nhận: $23 / 01 / 2021$
Ngày chỉnh sửa: $12 / 02 / 2021$
Ngày chấp nhận: 25/02/2021
Từ khóa
Phân đạm
Sả Java
Tinh dầu sả
*Tác giả liên hệ
Nguyễn Phạm Hồng Lan
Email: lan.nonghoc@hcmuaf.edu.vn

\section{1. Đặt Vấn Đề}

Cây sả Java (Cymbopogon winterianus Jawitt) là một trong những giống sả lấy tinh dầu được trồng phổ biến ở Việt Nam. Vì sả Java có hàm lượng geraniol và citronellol tương đối cao, có năng suất tinh dầu cao nhất trong các loại sả và trồng được trên nhiều loại đất khác nhau nên được sử dụng để chiết xuất tinh dầu trong sản xuất công nghiệp (Huynh, 2017). Tinh dầu sả Java có mùi thơm nồng đậm, thường dùng để khử mùi, lau nhà sát khuẩn, đuổi muỗi, kháng khuẩn, kháng viêm hiệu quả.

Theo Duong (2002), đạm là chất dinh dưỡng cần thiết và quan trọng đối với cây trồng, đặc biệt là cây sử dụng thân, lá. Đạm là nguyên tố tham gia vào thành phần chính của chlorophyll, protein, các axit amin, các enzyme và nhiều loại vitamin trong cây. Bón đạm giúp thúc đẩy quá trình tăng trưởng của cây, làm cho cây ra nhiều nhánh và lá, lá cây có kích thước to, màu xanh đậm, lá quang hợp mạnh, do đó làm tăng năng suất cho cây. Theo Zheljazkov \& ctv. (2011), thí nghiệm trên cây sả (Cymbopogon flexuosus (Steud) Wats.) cho thấy năng suất sinh khối tăng lên khi bón $80 \mathrm{~kg} \mathrm{~N} /$ ha và $160 \mathrm{~kg} \mathrm{~N} /$ ha tại vùng Verona và Poplarville thuộc Nam Mỹ. Năng suất sinh khối ở Verona dao động từ 9,5 - 19,4 kg/ha và sản lượng dầu dao động từ $30-139 \mathrm{~kg} / \mathrm{h}$. Còn ở vùng Poplarville, năng suất sinh khối dao động từ $8,0-12,6 \mathrm{~kg} / \mathrm{ha}$ và sản lượng dầu dao động từ $23,5-89,5 \mathrm{~kg} / \mathrm{h}$. Theo Pham \& ctv. (2019a), thí nghiệm trên cây sả Java (Cymbopogon winterianus Jawitt) tại Gia Lai cho thấy khi tăng liều lượng phân đạm từ 0 - $90 \mathrm{~kg} \mathrm{~N} /$ ha cho năng suất sả tăng vượt trội. Năng suất lá thực thu tại liều lượng $90 \mathrm{~kg} \mathrm{~N} /$ ha làm tăng khối lượng lá sả tới 196,7\% và sản lượng tinh dầu cũng tăng tới $196,5 \%$ so với không bón N. Song những nghiên cứu về liều lượng phân đạm ảnh hưởng đến sinh trưởng và năng suất tinh dầu của cây sả Java tại Việt Nam, dặc biệt là tại khu vực thành phố Hồ Chí Minh vẫn còn khá hạn chế. Xuất phát từ thực tế trên, việc xác định liều lượng phân đạm phù hợp cho cây sả sinh trưởng, đạt năng suất và hiệu quả kinh tế là cần thiết để nghiên cứu. 


\section{Vật Liệu và Phương Pháp Thí Nghiệm}

Thí nghiệm được thực hiện tại trại thực nghiệm khoa Nông học, Trường Đại học Nông Lâm TP.HCM từ tháng 4/2020 đến tháng 11/2020.

\section{1. Điều kiện thí nghiệm}

Kết quả phân tích đất ở Bảng 1 cho thấy thành phần cơ giới đất là cát pha thịt, $\mathrm{pH}$ đất hơi chua, cần bổ sung thêm vôi $(500 \mathrm{~kg} / \mathrm{ha})$ dể tăng $\mathrm{pH}$; Hàm lượng chất hữu cơ trong đất ở mức nghèo, bón thêm phân chuồng (20 tấn/ha) để làm xốp đất và tăng hàm lượng hữu cơ trong đất; Hàm lượng đạm, lân trong đất ở mức rất nghèo, bón thêm đạm (theo tỉ lệ từng nghiệm thức) và lân (60 kg/ha) để tăng hàm lượng đạm, lân tổng số trong đất.

Bên cạnh đó, trong thời gian thực thí nghiệm có lượng mưa lớn, nhiệt độ trung bình $\left(28,4^{\circ} \mathrm{C}\right.$ - 29,3 $\left.3^{\circ} \mathrm{C}\right)$, độ ẩm trung bình $(65-79 \%)$. Đây là điều kiện phù hợp để trồng cây sả vào mùa mưa.

\subsection{Vật liệu thí nghiệm}

Nghiên cứu sử dụng giống sả Java 18 tháng tuổi từ Gia Lai, chiều cao cây trung bình 1,05 1,14 m, đường kính nhánh 2,93 - 3,02 cm, ít bị sâu bệnh hại. Sả giống khi được tách từ cây mẹ được cắt bỏ bớt phần lá phía trên, chỉ chừa lại phần thân nhánh và phần gốc lá. Ủ sả nơi râm mát, tưới nước đủ ẩm khoảng 5 - 7 ngày đến khi nhánh sả ra rễ non thì đem đi trồng. Phân đạm Urea $(46,3 \% \mathrm{~N} ; 1,0 \%$ Biuret; $0,4 \%$ độ ẩm) của Công ty cổ phần phân bón và hóa chất dầu khí PVFCCo. Phân super lân $\left(16 \% \mathrm{P}_{2} \mathrm{O}_{5} ; 11 \% \mathrm{~S}\right)$ của công ty cổ phần Super Phốt phát và Hóa Chất Lâm Thao. Phân kali clorua $\left(61 \% \mathrm{~K}_{2} \mathrm{O}\right)$ của công ty TNHH Phú Thịnh.

\subsection{Bố trí thí nghiệm}

Thí nghiệm đơn yếu tố được bố trí theo kiểu hoàn toàn ngẫu nhiên, 3 lần lặp lại và 6 nghiệm thức, bao gồm 6 mức phân đạm khác nhau (90 $\mathrm{kg} \mathrm{N} / \mathrm{ha}$ - đối chứng, $120 \mathrm{~kg} \mathrm{~N} / \mathrm{ha}, 150 \mathrm{~kg} \mathrm{~N} / \mathrm{ha}$, $180 \mathrm{~kg} \mathrm{~N} / \mathrm{ha}, 210 \mathrm{~kg} \mathrm{~N} / \mathrm{ha}, 240 \mathrm{~kg} \mathrm{~N} / \mathrm{ha}$ ) trên nền đất xám bạc màu tại Thủ Đức, thành phố Hồ Chí Minh.

Diện tích mỗi ô cơ sở là $11,44 \mathrm{~m}^{2}$. Tổng diện tích toàn khu thí nghiệm: 276,32 $\mathrm{m}^{2}$. Mật độ trồng: 40.000 cây/ha.

\subsection{Phương pháp bón phân}

Nền phân chung cho thí nghiệm (tính cho 1 ha):

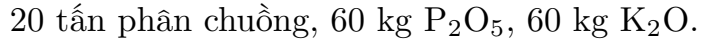

Bón lót: Bón toàn bộ phân bò + toàn bộ lân $+1 / 7 \mathrm{~N}+1 / 7 \mathrm{~K}_{2} \mathrm{O}$.

Bón thúc:

Lần 1: Sau khi bón lót 45 ngày (Sau khi trồng 45 - 55 ngày): $1 / 7 \mathrm{~N}+1 / 7 \mathrm{~K}_{2} \mathrm{O}$.

Lần 2: Sau khi bón thúc lần 1 khoảng 45 - 60 ngày: $1 / 7 \mathrm{~N}+1 / 7 \mathrm{~K}_{2} \mathrm{O}$.

Lần 3: Sau khi thu hoạch sả lần 1 (Sau khi bón thúc lần 2 khoảng $45-55$ ngày): $1 / 7 \mathrm{~N}+1 / 7$ $\mathrm{K}_{2} \mathrm{O}$.

Lần 4: Sau khi thu hoạch sả lần 2 (Khoảng 45 - 55 ngày sau khi thu hoạch sả là 1$): 1 / 7 \mathrm{~N}+1 / 7$ $\mathrm{K}_{2} \mathrm{O}$.

Cách bón: Rạch 2 bên gốc cách 10 - 15 cm, sâu $10 \mathrm{~cm}$ để bón phân sau đó lấp đất vùi kín phân.

\subsection{Các chỉ tiêu và phương pháp theo dõi}

Trên mỗi ô cơ sở đánh dấu 10 cây theo đường chéo gốc. Bắt đầu theo dõi từ 14 NST, định kì 14 ngày/lần và chia làm 2 đợt tương ứng với 2 đợt thu hoạch của thí nghiệm (Đợt 1 bắt đầu ở thời điểm 14 NST, 6 lần; Đợt 2 bắt đầu ở 104 NST, 3 lần đối với các chỉ tiêu sinh trưởng). Chiều cao cây $(\mathrm{cm} /$ cây) được đo từ gốc đến vuốt lá cao nhất. Số nhánh (nhánh/cây) là trung bình số nhánh có đủ 3 lá thấy rõ cổ lá của 10 cây. Số lá (lá/cây) là trung bình số lá trưởng thành thấy rõ cổ lá của 10 cây. Khối lượng lá trung bình 1 cây (g/cây) là trung bình của tổng khối lượng lá 10 cây. Năng suất lá thực thu (tấn/ha/đợt thu hoạch) là khối lượng lá thu hoạch được trên 1 ô cơ sở và quy về 1 ha. Hàm lượng tinh dầu $(\%)$ được chiết xuất bằng phương pháp lôi cuốn hơi nước. Năng suất tinh dầu thực thu $(\mathrm{kg} / \mathrm{ha} /$ đợt thu hoạch $)=($ Hàm lượng tinh dầu $(\% \mathrm{FW}) \times \mathrm{Năng}$ suất lá thực thu (tấn/ha/đợt thu hoạch) x 1.000)/100. Tỷ lệ phần trăm $(\%)$ các chất có trong tinh dầu sả được gửi mẫu phân tích tại Trung tâm kiểm nghiệm TSL. Hiệu quả tài chính tính quy về 1 ha.

\subsection{Phương pháp xử lí số liệu}

Số liệu được thu thập, tổng hợp, xử lý bằng phần mềm Excel 2010 và SAS 9.1. 
Bảng 1. Đặc điểm đất thí nghiệm

\begin{tabular}{|c|c|c|c|c|c|c|c|}
\hline \multicolumn{3}{|c|}{ Thành phần cơ giới (\%) } & \multicolumn{2}{|c|}{ pH : Đất dịch trích $(1: 2,5)$} & \multirow{2}{*}{$\begin{array}{l}\text { Chất hữu cơ } \\
(\%)\end{array}$} & \multirow{2}{*}{$\begin{array}{c}\text { Đạm tổng số } \\
\left(\mathrm{N}_{\mathrm{ts}}\right)(\%) \\
\end{array}$} & \multirow{2}{*}{$\begin{array}{l}\text { Lân tổng số } \\
\left(\mathrm{N}_{\mathrm{ts}}\right)(\%)\end{array}$} \\
\hline Cát & Thịt & Sét & $\mathrm{H}_{2} \mathrm{O}$ & $\mathrm{KCl}$ & & & \\
\hline 61,80 & 32,90 & 5,30 & 5,30 & 4,20 & 0,80 & 0,04 & 0,02 \\
\hline
\end{tabular}

Bảng 2. Ảnh hưởng của lượng phân đạm đến sinh trưởng thân, lá của cây sả Java

\begin{tabular}{ccccccc}
\hline \multirow{2}{*}{ Lượng N bón $(\mathrm{kg} \mathrm{N} / \mathrm{ha})$} & \multicolumn{2}{c}{ Chiều cao cây $(\mathrm{cm} /$ cây) } & Số nhánh & (nhánh/cây) & \multicolumn{2}{c}{ Số lá (lá/cây) } \\
\cline { 2 - 7 } & $84 \mathrm{NST}$ & $132 \mathrm{NST}$ & $84 \mathrm{NST}$ & $132 \mathrm{NST}$ & 84 NST & 132 NST \\
\hline $90(\mathrm{DC})$ & $96,2^{\mathrm{ab}}$ & 95,5 & 76,7 & $105,3^{\mathrm{a}}$ & $165,6^{\mathrm{ab}}$ & $189,4^{\mathrm{ab}}$ \\
120 & $100,8^{\mathrm{a}}$ & 97,0 & 62,0 & $86,3^{\mathrm{b}}$ & $173,7^{\mathrm{a}}$ & $197,1^{\mathrm{a}}$ \\
150 & $87,8^{\mathrm{bc}}$ & 86,5 & 54,7 & $84,3^{\mathrm{b}}$ & $159,4^{\mathrm{ab}}$ & $178,4^{\mathrm{ab}}$ \\
180 & $89,7^{\mathrm{bc}}$ & 92,1 & 50,3 & $85,0^{\mathrm{b}}$ & $141,3^{\mathrm{c}}$ & $131,4^{\mathrm{c}}$ \\
210 & $91,7^{\mathrm{abc}}$ & 87,7 & 56,3 & $84,0^{\mathrm{b}}$ & $151,7^{\mathrm{bc}}$ & $168,4^{\mathrm{b}}$ \\
240 & $80,5^{\mathrm{c}}$ & 85,1 & 47,7 & $84,7^{\mathrm{b}}$ & $154,6^{\mathrm{bc}}$ & $178,4^{\mathrm{ab}}$ \\
\hline CV (\%) & 7,1 & 14,3 & 18,5 & 8,6 & 6,3 & 7,7 \\
$F_{\text {tính }}$ & $3,5^{*}$ & $0,5^{\mathrm{ns}}$ & $2,9^{\mathrm{ns}}$ & $3,7^{*}$ & $3,9^{*}$ & $9,1^{* *}$ \\
\hline
\end{tabular}

a-c Trên cùng một cột các trị số có cùng ký tự đi kèm khác biệt không có ý nghĩa thống kê. ns : khác biệt không có ý nghĩa thống kê; * : khác biệt có ý nghĩa thống kê $(\alpha \leq 0,05)$; $^{* *}$ : khác biệt rất có ý nghĩa thống kê $(\alpha \leq 0,01)$.

\section{Kết Quả Và Thảo Luận}

\section{1. Ảnh hưởng của liều lượng phân đạm đến sinh trưởng cây sả Java}

Kết quả Bảng 2 cho thấy chiều cao cây sả đạt cao nhất khi bón $120 \mathrm{~kg} \mathrm{~N} /$ ha $(100,8 \mathrm{~cm})$ tại 84 NST (thu hoạch đợt 1), khác biệt không có ý nghĩa so với bón 90 và $210 \mathrm{~kg} \mathrm{~N} /$ ha nhưng khác biệt có ý nghĩa thống kê so với các nghiệm thức còn lại. Ở 132 NST (thu hoạch đợt 2), chiều cao cây khác biệt không có ý nghĩa thống kê giữa các nghiệm thức và dao động từ $85,1-97,0 \mathrm{~cm} /$ cây. Chiều cao cây của thí nghiệm thấp hơn so với chiều cao cây sả Java trong nghiên cứu của Pham \& ctv. (2019b) trồng tại tỉnh Gia Lai ở thời điểm 55 NSBP (thu hoạch đợt 2) đạt cao nhất (120,2 $\mathrm{cm})$ khi bón $90 \mathrm{~kg} \mathrm{~N} /$ ha. Do cây sả trong thí nghiệm được trồng mới nên ảnh hưởng của phân bón đến sinh trưởng chưa rõ rệt.

Kết quả Bảng 2 cũng cho thấy số nhánh sả khác biệt không có ý nghĩa thống kê giữa các nghiệm thức và dao động từ 47,7 - 62,0 nhánh/cây tại 84 NST. Ở 132 NST, số nhánh đạt cao nhất khi bón $90 \mathrm{~kg} \mathrm{~N} /$ cây (105,3 nhánh/cây), khác biệt có ý nghĩa thống kê so với các nghiệm thức còn lại.

Tại 84 NST, số lá sả đạt cao nhất khi bón 120 kg N/ha (173,7 lá/cây), khác biệt không có ý nghĩa thống kê so với khi bón 90 và $150 \mathrm{~kg} \mathrm{~N} /$ ha nhưng khác biệt có ý nghĩa thống kê so với các nghiệm thức còn lại. Ở 132 NST, số lá sả cao nhất khi bón 120 kg/ha (197,1 lá/cây), khác biệt không có ý nghĩa thống kê với khi bón 90, 150 và $240 \mathrm{~kg} \mathrm{~N} /$ ha nhưng khác biệt rất có ý nghĩa thống kê so với các nghiệm thức còn lại.

\section{2. Ảnh hưởng của liều lượng phân đạm đến năng suất lá sả Java}

Kết quả Bảng 3 cho thấy khối lượng lá trung bình 1 cây đạt cao nhất khi bón $120 \mathrm{~kg} \mathrm{~N} / \mathrm{ha}$ (166,7 g/cây), khác biệt không có ý nghĩa thống kê so với bón 90 và $240 \mathrm{~kg} \mathrm{~N} /$ ha ở $84 \mathrm{NST}$ (thu hoạch đợt 1) nhưng khác biệt có ý nghĩa thống kê với các nghiệm thức còn lại. Ở 132 NST (thu hoạch đợt 2), khối lượng lá trung bình 1 cây đạt cao nhất khi bón $120 \mathrm{~kg} \mathrm{~N} /$ ha (198,7 g/cây), khác biệt không có ý nghĩa thống kê so với khi bón 90 và $180 \mathrm{~kg} \mathrm{~N} /$ ha nhưng khác biệt có ý nghĩa thống kê với các nghiệm thức còn lại.

Kết quả Bảng 3 cũng cho thấy năng suất lá thực thu ở cả 2 đợt thu hoạch khác biệt rất có ý nghĩa trong thống kê giữa các nghiệm thức. Năng suất lá thực thu đạt cao nhất khi bón 120 $\mathrm{kg} \mathrm{N} /$ ha (lần lượt là 4,4 tấn/ha ở 84 NST; 5,0 tấn/ha ở 132 NST và 9,4 tấn/ha ở cả 2 đợt thu hoạch), khác biệt không có ý nghĩa thống kê với đối chứng bón $90 \mathrm{~kg} \mathrm{~N} /$ ha nhưng khác biệt rất ý nghĩa thống kê so với các nghiệm thức còn lại. Điều này cho thấy năng suất lá sả có xu hướng tăng ở năm sau so với nghiên cứu của Wany \& ctv. (2013) là năng suất lá sả năm thứ nhất dao động từ 4,2 - 5,6 tấn/ha/2 đợt thu hoạch. 
Bảng 3. Ảnh hưởng của lượng phân đạm đến khối lượng trung bình 1 cây và năng suất lá thực thu của cây sả Java

\begin{tabular}{|c|c|c|c|c|c|}
\hline \multirow{2}{*}{ Lượng N bón (kg N/ha) } & \multicolumn{2}{|c|}{$\begin{array}{l}\text { Khối lượng trung bình } 1 \text { cây } \\
\qquad(\mathrm{g} / \text { cây })\end{array}$} & \multicolumn{2}{|c|}{$\begin{array}{l}\text { Năng suất lá thực thu } \\
\text { (tấn/ha/đợt thu hoạch) }\end{array}$} & \multirow{2}{*}{ Tổng 2 đợt } \\
\hline & $84 \mathrm{NST}$ & $132 \mathrm{NST}$ & $84 \mathrm{NST}$ & $132 \mathrm{NST}$ & \\
\hline $90(\mathrm{DC})$ & $164,3^{\mathrm{ab}}$ & $189,0^{\mathrm{ab}}$ & $4,1^{\mathrm{a}}$ & $4,9^{\mathrm{a}}$ & $9,1^{\mathrm{a}}$ \\
\hline 120 & $166,7^{\mathrm{a}}$ & $198,7^{\mathrm{a}}$ & $4,4^{\mathrm{a}}$ & $5,0^{\mathrm{a}}$ & $9,4^{\mathrm{a}}$ \\
\hline 150 & $146,0^{\mathrm{bc}}$ & $175,3^{\mathrm{bc}}$ & $2,9^{\mathrm{b}}$ & $4,7^{\mathrm{ab}}$ & $7,6^{\mathrm{b}}$ \\
\hline 180 & $140,3^{\mathrm{c}}$ & $185,0^{\mathrm{abc}}$ & $3,1^{\mathrm{b}}$ & $4,1^{\mathrm{bc}}$ & $7,2^{\mathrm{bc}}$ \\
\hline 210 & $143,7^{\mathrm{b}}$ & $182,8^{\mathrm{bc}}$ & $2,8^{\mathrm{b}}$ & $3,9^{\mathrm{c}}$ & $6,6^{\mathrm{c}}$ \\
\hline 240 & $154,3^{\mathrm{abc}}$ & $174,7^{\mathrm{c}}$ & $2,8^{\mathrm{b}}$ & $4,0^{\mathrm{c}}$ & $6,8^{\mathrm{c}}$ \\
\hline $\mathrm{CV}(\%)$ & 6,6 & 4,2 & 10,0 & 8,1 & 5,1 \\
\hline $\mathrm{F}_{\text {tính }}$ & $3,6^{*}$ & $4,1^{*}$ & $14,1^{* *}$ & $5,8^{* *}$ & $0,0^{* *}$ \\
\hline
\end{tabular}

a-c Trên cùng một cột các trị số có cùng ký tự đi kèm khác biệt không có ý nghĩa thống kê. * : khác biệt có ý nghĩa thống kê $(\alpha \leq 0,05),{ }^{* *}$ : khác biệt rất có ý nghĩa thống kê $(\alpha \leq 0,01)$.

Bảng 4. Ảnh hưởng của lượng phân đạm đến hàm lượng tinh dầu và năng suất tinh dầu thực thu của cây sả Java

\begin{tabular}{cccccc}
\hline \multirow{2}{*}{ Lượng N bón (kg N/ha) } & \multicolumn{2}{c}{$\begin{array}{c}\text { Hàm lượng tinh dầu } \\
(\%)\end{array}$} & \multicolumn{2}{c}{$\begin{array}{c}\text { Năng suất tinh dầu thực thu } \\
\text { (kg/ha/dợt thu hoạch) }\end{array}$} & Tổng 2 đợt \\
\cline { 2 - 5 } & $84 \mathrm{NST}$ & $132 \mathrm{NST}$ & $84 \mathrm{NST}$ & $132 \mathrm{NST}$ & \\
\hline 90 & $0,9^{\mathrm{b}}$ & 1,0 & $36,6^{\mathrm{b}}$ & $48,9^{\mathrm{ab}}$ & $85,5^{\mathrm{b}}$ \\
120 & $1,0 \mathrm{a}$ & 1,0 & $45,0^{\mathrm{a}}$ & $52,9^{\mathrm{a}}$ & $97,8^{\mathrm{a}}$ \\
150 & $0,9^{\mathrm{b}}$ & 0,9 & $26,6^{\mathrm{c}}$ & $43,2^{\mathrm{abc}}$ & $69,7^{\mathrm{c}}$ \\
180 & $0,9^{\mathrm{b}}$ & 1,0 & $27,6^{\mathrm{c}}$ & $40,4^{\mathrm{bc}}$ & $68,0 \mathrm{c}$ \\
210 & $0,9^{\mathrm{b}}$ & 1,0 & $24,7^{\mathrm{c}}$ & $38,3^{\mathrm{c}}$ & $63,0^{\mathrm{c}}$ \\
240 & $0,7^{\mathrm{c}}$ & 1,0 & $20,2^{\mathrm{c}}$ & $38,6 \mathrm{c}$ & $58,8^{\mathrm{c}}$ \\
\hline $\mathrm{CV}(\%)$ & 6,3 & 5,2 & 14,6 & 12,2 & $8,7^{*}$ \\
$\mathrm{~F}_{\text {tính }}$ & $9,7^{* *}$ & $2,6^{\mathrm{ns}}$ & $12,8^{* *}$ & $3,7^{*}$ & $0,0^{* *}$ \\
\hline
\end{tabular}

a-c Trên cùng một cột các trị số có cùng ký tự đi kèm khác biệt không có ý nghĩa thống kê. * : khác biệt có ý nghĩa thống kê $(\alpha \leq 0,05),{ }^{* *}$ : khác biệt rất có ý nghĩa thống kê $(\alpha \leq 0,01)$.

\section{3. Ảnh hưởng của liều lượng phân đạm đến năng suất và chất lượng tinh dầu của cây sả Java}

Kết quả Bảng 4 cho thấy ở 84 NST (thu hoạch đợt 1), cây sả Java cho hàm lượng tinh dầu cao nhất (1,0\%) khi được bón $120 \mathrm{~kg} \mathrm{~N} /$ ha, khác biệt rất có ý nghĩa thống kê so với các nghiệm thức còn lại. Hàm lượng tinh dầu tại 132 NST (thu hoạch đợt 2) dao động từ $0,9-1,0 \%$, khác biệt không có ý nghĩa thống kê giữa các nghiệm thức. Điều này tương tự với nghiên cứu của Wany \& ctv. (2013) là hàm lượng tinh dầu trong lá sả Java trung bình là $1 \%$.

Kết quả Bảng 4 cũng cho thấy năng suất tinh dầu thực thu ở 84 NST và tổng 2 đợt thu hoạch khi được bón $120 \mathrm{~kg} \mathrm{~N} /$ ha đạt cao nhất (lần lượt là 45,0 và $97,8 \mathrm{~kg} / \mathrm{ha} /$ đợt thu hoạch), khác biệt rất có ý nghĩa thống kê so với các nghiệm thức còn lại.
Ở 132 NST, năng suất tinh dầu thực thu cây sả đạt cao nhất khi bón $120 \mathrm{~kg} \mathrm{~N} / \mathrm{ha}(52,87 \mathrm{~kg} / \mathrm{ha})$, khác biệt không có ý nghĩa thống kê so với nghiệm thức đối chứng bón 90 và $150 \mathrm{~kg} \mathrm{~N} /$ ha nhưng khác biệt có ý nghĩa trong thống kê so với các nghiệm thức còn lại.

Nghiên cứu của Pham \& ctv. (2019b) thể hiện năng suất tinh dầu sả Java thực thu cao nhất đạt chỉ 46,9 kg/ha/đợt thu hoạch khi bón $90 \mathrm{~kg} \mathrm{~N} / \mathrm{ha}$ tại 55 NSBP (thu hoạch đợt 2), thấp hơn so với kết quả của thí nghiệm ở cùng mức phân đạm.

Kết quả Bảng 5 cho thấy các chất Citronellal, Citronellol và Geraniol chiếm tỷ lệ phần trăm cao nên là thành phần chính trong tinh dầu sả Java. Trong đó, Citronellal cao nhất ở hai mức bón $150 \mathrm{~kg} \mathrm{~N} /$ ha và $240 \mathrm{~kg} \mathrm{~N} /$ ha $(37,7 \%)$. Khi bón $90 \mathrm{~kg} \mathrm{~N} / \mathrm{ha} /$ năm cho Citronellol và Genariol cao nhất so với các nghiệm thức còn lại, lần lượt là $15,4 \%$ và $26,6 \%$. Theo Nakahara \& ctv. (2013), 
Bảng 5. Tỷ lệ phần trăm $(\%)$ các chất có trong tinh dầu sả Java khi bón lượng đạm khác nhau

\begin{tabular}{|c|c|c|c|c|c|c|c|c|}
\hline \multirow{2}{*}{ Thành phần đơn hương ${ }^{(2)}$} & \multicolumn{6}{|c|}{ Mức phân bón đạm (kg N/ha/năm) } & \multirow{2}{*}{$\mathrm{CV}(\%)$} & \multirow{2}{*}{$\mathrm{F}_{\text {tính }}$} \\
\hline & $90(\mathrm{DC})$ & 120 & 150 & 180 & 210 & 240 & & \\
\hline Citronellal & $31,4^{\mathrm{bc}}$ & $33,3^{b}$ & $37,7^{\mathrm{a}}$ & $29,9^{\mathrm{c}}$ & $29,3^{\mathrm{c}}$ & $37,7^{\mathrm{a}}$ & 3,8 & $26,7^{* *}$ \\
\hline Geraniol & $26,6^{\mathrm{a}}$ & $18,4^{\mathrm{c}}$ & $24,8^{\mathrm{b}}$ & $24,5^{\mathrm{b}}$ & $24,6^{\mathrm{b}}$ & $24,7^{\mathrm{b}}$ & 2,8 & $54,4^{* *}$ \\
\hline Citronellol & $15,4^{\mathrm{a}}$ & $12,2^{\mathrm{c}}$ & $14,8^{\mathrm{ab}}$ & $14,1^{\mathrm{ab}}$ & $13,6^{\mathrm{b}}$ & $13,9^{\mathrm{b}}$ & 3,6 & $14,1^{* *}$ \\
\hline Limonene & 1,6 & 3,0 & 1,4 & 1,8 & 1,8 & 1,5 & - & - \\
\hline Linalool & 0,4 & 0,7 & 0,3 & 0,3 & 0,3 & 0,2 & - & - \\
\hline$\beta$-Citral & 0,9 & 0,6 & 0,7 & 0,7 & 0,6 & 0,6 & - & - \\
\hline$\alpha$-Citral & 0,9 & 0,8 & 0,7 & 0,9 & 0,8 & 0,6 & - & - \\
\hline Citronellol acetate & 3,3 & 2,3 & 2,6 & 4,0 & 4,2 & 3,0 & - & - \\
\hline Eugenol & 0,4 & 0,8 & 0,3 & 0,4 & 0,4 & 0,2 & - & - \\
\hline Geranyl acetate & - & 1,9 & 4,3 & 5,8 & 6,1 & 4,5 & - & - \\
\hline$\beta$-Emelene & 1,1 & 1,2 & 0,9 & 1,6 & 1,9 & 1,4 & - & - \\
\hline Elemol & 7,0 & 6,1 & 6,5 & 8,0 & 8,0 & 6,3 & - & - \\
\hline$\beta$-Nerol & 0,3 & - & 0,2 & 0,2 & 0,2 & 0,2 & - & - \\
\hline Germacrene D & 0,5 & - & 0,5 & 0,9 & 1,1 & 0,8 & - & - \\
\hline$\Delta$-Cadinene & 0,6 & - & 0,6 & 0,9 & 1,1 & 0,7 & - & - \\
\hline Germacrene D-4-ol & 0,4 & - & 0,3 & 4,3 & 4,1 & 3,0 & - & - \\
\hline$\alpha$-Cadinol & 0,6 & - & 0,6 & 0,8 & 0,9 & 0,5 & - & - \\
\hline
\end{tabular}

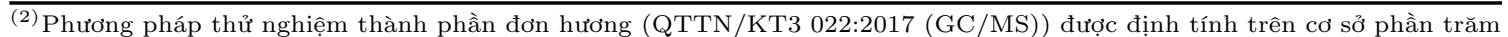
diện tích peak của các hợp chất hữu cơ bay hơi (Trung tâm kỹ thuật tiêu chuẩn đo lường chất lượng 3,2020 ).

${ }^{a-c}$ Trên cùng một cột các trị số có cùng ký tự đi kèm khác biệt không có ý nghĩa thống kê. **: khác biệt rất có ý nghĩa thống kê $(\alpha \leq 0,01)$; $(-)$ : Thành phần không tồn tại hoặc không xử lý thống kê.

Bảng 6. Hiệu quả tài chính của việc trồng sả Java tính trên 1 ha khi bón lượng đạm khác nhau

\begin{tabular}{|c|c|c|c|c|}
\hline Lượng $\mathrm{N}$ bón (kg N/ha) & \multicolumn{3}{|c|}{ (triệu đồng/ha/2 đợt thu hoạch) } & Tỷ suất lợi nhuận (lần) \\
\hline $90(\mathrm{DC})$ & $85,5^{\mathrm{b}}$ & $36,7^{\mathrm{e}}$ & $48,8^{\mathrm{b}}$ & $1,3^{b}$ \\
\hline 120 & $97,8^{\mathrm{a}}$ & $37,8^{\text {de }}$ & $60,0^{\mathrm{a}}$ & $1,6^{\mathrm{a}}$ \\
\hline 150 & $69,7^{\mathrm{c}}$ & $38,9^{\mathrm{cd}}$ & $30,8^{\mathrm{c}}$ & $0,8^{\mathrm{c}}$ \\
\hline 180 & $68,0^{\mathrm{c}}$ & $40,0^{\mathrm{bc}}$ & $27,0^{\mathrm{c}}$ & $0,7^{\mathrm{cd}}$ \\
\hline 210 & $63,0^{\mathrm{c}}$ & $41,2^{\mathrm{ab}}$ & $21,8^{\mathrm{d}}$ & $0,5^{\mathrm{de}}$ \\
\hline 240 & $58,8^{\mathrm{c}}$ & $42,3^{\mathrm{a}}$ & $16,5^{\mathrm{e}}$ & $0,4^{\mathrm{e}}$ \\
\hline $\mathrm{CV}(\%)$ & 8,7 & 1,9 & 5,4 & 7,5 \\
\hline $\mathrm{F}_{\text {tính }}$ & $16,1^{* *}$ & $23,15^{* *}$ & $250,3^{* *}$ & $156,3^{* *}$ \\
\hline
\end{tabular}

Giá bán giả định 1.000 .000 đồng/kg tinh dầu. Tổng chi gồm: phân bón (phân nền và phân $\mathrm{N}$ ), giống, thuốc bảo vệ thực vật, nhân công, khấu hao trang thiết bị và vật tư nông nghiệp, chi phí điện nước. Tổng thu = Năng suất tinh dầu thực thu x giá bán giả định. Lợi nhuận = Tổng thu - Tổng chi. Tỷ suất lợi nhuận = Lợi nhuận/Tổng chi.

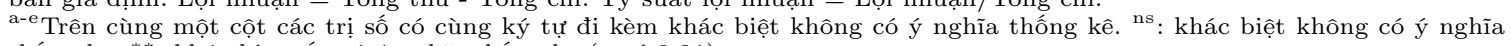
thống kê; **: khác biệt rất có ý nghĩa thống kê $(\alpha \leq 0,01)$.

tỷ lệ các thành phần chính của tinh dầu sả là geraniol $(35,7 \%)$, citronellal $(5,8 \%)$ và citronellol (4,6\%). Nghiên cứu khác của Zhang \& ctv. (2011), tỷ lệ các thành phần chính của tinh dầu sả là Geraniol $(16,54 \%)$, citronellal $(15,44 \%)$, citronellol (11,51\%). Điều này cho thấy việc bổ sung $\mathrm{N}$ có tác động thay đổi tỷ lệ phần trăm các thành phần trong tinh dầu. Bảng 5 cho thấy Citrinellal và Citronellol đều chiếm tỷ lệ phần trăm cao hơn so với hai nghiên cứu trên nhưng Geraniol lại thấp hơn. Tuy nhiên, kết quả Bảng 5 chủ yếu thể hiện tỷ lệ phần trăm tính trên sự hiện diện của tất cả các chất có trong tinh dầu sả, chưa xác định được chính xác hàm lượng (mg) hoạt chất chính có trong $1 \mathrm{~kg}$ tinh dầu nên chưa thể kết luận chính xác về ảnh hưởng của liều lượng $\mathrm{N}$ đến chất lượng tinh dầu sả Java.

Kết quả Bảng 6 cho thấy tổng thu giữa các mức phân N bón khác nhau lại khác biệt không có ý nghĩa thống kê. Tuy nhiên, tổng chi của nghiệm thức đối chứng thấp nhất (36,7 triệu đồng/ha/2 đợt thu hoạch) khác biệt không có ý nghĩa thống kê so với khi bón $120 \mathrm{~kg} \mathrm{~N} /$ ha nhưng khác biệt rất có ý nghĩa thống kê so với các nghiệm thức còn 
lại. Trong khi đó, lợi nhuận thu được càng cao khi tổng thu cao và tổng chi thấp. Nghiệm thức có mức bón $120 \mathrm{~kg} \mathrm{~N} /$ ha thỏa điều kiện trên với lợi nhuận cao nhất đạt 60,0 triệu đồng/ha/2 đợt thu hoạch với tỷ suất lợi nhuận là 1,6 lần, khác biệt rất có ý nghĩa thống kê so với các mức bón còn lại kể cả đối chứng. Vì vậy, trong phạm vi kết quả thí nghiệm, hiệu quả tài chính do ảnh hưởng của liều lượng phân $\mathrm{N}$ bón, đặc biệt là khi bón 120 $\mathrm{kg} \mathrm{N} /$ ha đến sinh trưởng và năng suất của cây sả Java thực sự có ý nghĩa trong thực tiễn sản xuất cây sả lấy tinh dầu tại TP.HCM nói riêng.

\section{Kết Luận và Đề Nghị}

\subsection{Kết luận}

Bón $120 \mathrm{~kg}$ N/ha cho cây sả Java đạt kết quả vượt trội về chiều cao cây $(97,0 \mathrm{~cm} /$ cây $)$, số lá (197,1 lá/cây), khối lượng lá trung bình 1 cây $(198,7 \mathrm{~g} /$ cây), năng suất lá thực thu $(9,4$ tấn/ha/2 đợt thu hoạch), hàm lượng tinh dầu (1,0\% FW), năng suất tinh dầu thực thu $(97,8$ $\mathrm{kg} / \mathrm{ha} / 2$ đợt thu hoạch), mang lại lợi nhuận cao nhất đạt 60,0 triệu đồng/ha/2 đợt thu hoạch với tỷ suất lợi nhuận là 1,6 lần.

\section{2. Đề nghị}

Khuyến cáo sử dụng phân đạm ở liều lượng 120 $\mathrm{kg} \mathrm{N} /$ ha cho sả Java lấy tinh dầu 18 tháng tuổi, trồng luống trên nền đất xám bạc màu tại Thủ Đức, TP.HCM.

Cần tiến hành thu hoạch thêm nhiều đợt nữa để có được kết luận chính xác về ảnh hưởng của liều lượng $\mathrm{N}$ đến năng suất tinh dầu sả Java.

Cần tiến hành phân tích hàm lượng Citronellal và Geraniol bằng phương pháp TS - KT - SK 135:2020 để có được kết luận chính xác về ảnh hưởng của liều lượng $\mathrm{N}$ đến chất lượng tinh dầu sả Java.

\section{Tài Liệu Tham Khảo (References)}

Duong, D. H. (2002). Fertilizer handbook. Ha Noi, Vietnam: Ha Noi Publishing House.

Huynh, H. Q. (2017). Effects of nitrogen fertilizer dosage on growth and yield of Cymbopogon winterianus Jawitt in Gia Lai province (Unpublished master's thesis). Nong Lam University, Ho Chi Minh City, Vietnam.

Nakahara, K., Alzoreky, N. S., Yoshihashi, T., Nguyen, H. T. T., \& Trakoontivakorn, G. (2013). Chemical composition and antifungal activity of essential oil from Cymbopogon nardus (Citronella grass). Japan Agricultural Research Quarterly: JARQ 37(4), 249-252.

Pham, T. T. M., Dao, H. D., Nguyen, L. P. H., Pham, C. A., Vu, A. T., Vo, O. T. T., Nguyen, N. D., \& Nguyen, P. V. (2019a). Effects of nitrogen and phosphate dosage on growth and Cymbopogon winterianus Jawitt in Gia Lai province. Science and Technology Journal of Agriculture and Rural Development 1, 4350.

Pham, T. T. M., Nguyen, L. P. H., Pham, C. A., Huynh, H. Q., Dao, H. D., Nguyen, N. D., \& Vo, O. T. T. (2019b). Effects of nitrogen fertilizer dosage on growth and yield of lemongrass Java (Cymbopogon winterianus Jawitt) in Gia Lai province. The Journal of Agriculture and Development 18(2), 57-64.

Wany, A., Jha, S., Nigam, V. K., \& Pandey, D. M. (2013). Review article: Chemical analysis and therapeutic uses of citronella oil from Cymbopogon winterianus: A short review. International Journal of Advanced Research $1(6), 504-521$.

Zhang, S. J., Zhao, N. N., Liu, Z. Q., Liu, Z. L., Du, S. S., Zhou, L., \& Deng, J. W. (2011). Repellent constituents of essential oil of Cymbopogon distans aerial parts against two stored-product insects. Journal of Agricultural and Food Chemistry 59(18), 9910-9915.

Zheljazkov, V. D., Cantrell, C. L., Astatkie, T., \& Cannon, J. B. (2011). Lemongrass productivity, oil content, and composition as a function of nitrogen, sulfur, and harvest time. Agronomy Journal 103(3), 805-812. 